\title{
A huff-and-puff production of gas hydrate deposits in Shenhu area of South China Sea through a vertical well
}

\author{
Zheng Su ${ }^{\mathrm{a}, \mathrm{b}}$, George J. Moridis ${ }^{\mathrm{c}}$, Keni Zhang ${ }^{\mathrm{d}}$, Nengyou Wu ${ }^{\mathrm{a}, \mathrm{b}, *}$ \\ a Key Laboratory of Renewable Energy and Gas Hydrate, Guangzhou Institute of Energy Conversion,Chinese Academy of Sciences, Guangzhou 510640, China \\ b Guangzhou Center for Gas Hydrate Research, Chinese Academy of Sciences, Guangzhou 510640, China \\ ${ }^{\text {c }}$ Lawrence Berkeley National Laboratory, Berkeley, CA 94702, USA \\ d College of Water Sciences, Beijing Normal University, Beijing 100875, China
}

\section{A R T I C L E I N F O}

\section{Article history:}

Received 12 August 2011

Accepted 15 March 2012

Available online 26 March 2012

\section{Keywords:}

gas hydrates

Shenhu area

hydrate dissociation

huff-and-puff

numerical simulation

\begin{abstract}
A B S T R A C T
The Shenhu area on the northern continental slope of the South China Sea is one of the most promising fields for gas hydrate exploitation. Drilling and sampling has indicated high saturations of methane hydrate in clay silty sediments at drilling site SH2. The hydrate-bearing layer is overlain and underlain by permeable zones of mobile water, and the system does not appear to be bounded by low-permeability strata. In this study a huffand-puff method is used to producing gas from the hydrate accumulation. We simulate numerically the hydrate dissociation and gas production by alternately injecting hot water and producing fluids at a vertical well. The simulations show the gas production rate in huff-and-puff operations is very small $\left(50-140 \mathrm{~m}^{3} /\right.$ d), and unacceptable for commercial production. The calculation also indicated secondary hydrates forms at the very early period of injecting operations, and then gas is released due to the thermal stimulation of hot water, but the amount of released gas in the injection periods of hot water is much smaller than that converts into secondary hydrates. In the production operations, much of gas is released from the hydrates due to a small depressurization at the well, but the released gas can not produce effectively due to the small pressure gradient, and thus remains in the reservoir and converts into secondary hydrates in the next operation of injecting hot water. The study provides an insight into the production potential of the Shenhu hydrate accumulations through the huff-and-puff method, and a basis for the analysis of the economic feasibility of gas production from that area.
\end{abstract}

(c) 2012 Elsevier B.V. All rights reserved.

\section{Introduction}

Gas hydrates are crystalline substances composed of water and gas, in which a solid water lattice accommodates gas molecules in a cagelike structure (Sloan, 1998). The estimated amount of gas in the hydrate accumulations of the world greatly exceeds the volume of known conventional gas resources (Sloan, 1998). Because of their potential importance as an energy resource, $\mathrm{CH}_{4}$-hydrates are currently attracting significant attention. However, the role that gas hydrates may play in contributing to the world's energy requirements will depend ultimately on the availability of producible gas hydrate resources and the cost to extract them (Moridis et al., 2004).

The four main methods of hydrate dissociation for producing gas include (Makogon, 1987, 1997): (1) depressurization, in which the pressure is lowered to a level lower than the hydration pressure $\mathrm{P}_{\mathrm{H}}$ at the prevailing temperature (Moridis et al., 2007, 2009a); (2) thermal

\footnotetext{
* Corresponding author at: Key Laboratory of Renewable Energy and Gas Hydrate, Guangzhou Institute of Energy Conversion, Chinese Academy of Sciences, Guangzhou 510640, China. Tel.: + 862087052746 .

E-mail address: wuny@ms.giec.ac.cn (N.Wu).
}

stimulation, in which the temperature is raised above the hydration temperature $T_{H}$ at the prevailing pressure (Moridis et al., 2004); (3) the use of inhibitors (such as salts and alcohols), which causes a shift in the $\mathrm{P}_{\mathrm{H}}-\mathrm{T}_{\mathrm{H}}$ equilibrium through competition with the hydrate for guest and host molecules (Sloan, 1998); and (4) a combination of these methods (Li et al., 2010). In gas production from hydrate deposits depressurization and thermal stimulation are considered as the relatively feasible method both economically and technically (Moridis and Reagan, 2007a, 2007b; Moridis et al., 2009a, 2009b, 2011). The Mallik 2002 well demonstrated proof of concept that it is possible to recover energy from permafrost hydrates combining dissociation techniques of depressurization and thermal stimulation (Sloan and Koh, 2008). The huff-and-puff method, also known as cyclic steam stimulation (CSS), was accidentally discovered by Shell Oil Company in 1960 during a Venezuela recovery project, and is widely used in the oil industry to enhance oil recovery (Sayegh and Maini, 1984; Vittoratos, 1991; Leaute and Carey, 2007). The hot water, hot brine or steam huff-and-puff method is a special form of the combination of depressurization and thermal stimulation methods for gas production from hydrate deposit (Li et al., 2011).

Shenhu is near southeast of Shenhu Underwater Sandy Bench in the middle of the north slope of the SCS, between Xisha Trough and 
Dongsha Islands (Fig. 1). Geological, geophysical, geothermal, and geochemical investigations have suggested that Shenhu area is a favorable place for the formation of natural gas hydrates (Wu et al., 2008,2010 ). Based on the indications of hydrate presence, five sites were selected for deep drilling and sampling in the Shenhu area (Fig. 1), and core samples were collected chronologically from $\mathrm{SH} 3$, SH1, SH2, SH7, and SH5 (Wu et al., 2008). Depressurization experiments verified the existence of methane gas hydrates in the clay silty cores sampled from SH2, SH3, and SH7 at the water depth of 1108-1235 m. (Li et al., 2010; Su et al., 2011). The Hydrate-Bearing Layer (hereafter referred to as $\mathrm{HBL}$ ) is $40 \mathrm{~m}$ thick and the hydrate saturation ranges from 0 to $48 \%$ at drilling site $\mathrm{SH} 2$ which implies a huge amount of natural gas stored in the hydrate deposits. Some simulations have provided the first insight into the technical feasibility of gas production from the promising accumulations by depressurization method (Li et al., 2010; Su et al., 2011).

The main objective of this study is to assess the production potential of the hydrate deposit at the drilling Site SH2 by means of huff-and-puff. Parameters used in the reference cases are measured from the samples, such as saturations, temperature and pressure, and deposit permeability is estimated based on the properties lithology. Because of the possible imprecision of the measured data from the unconsolidated samples and uncertain geological structure, a large number of these parameters are treated as perturbation variables in the ensuing sensitivity analysis.

In evaluating the production potential of hydrate deposits in huffand-puff operations, we use the two criteria, an absolute criterion and a relative criterion (Moridis et al., 2009a). To satisfy the absolute criterion, a large production potential must be demonstrated, as quantified by a large gas production rate $Q_{p}$, a large cumulative gas production volume $V_{P}$ over the duration of the production. The relative criterion is satisfied when the gas-to-water ratio $R_{G W}=V_{G} / V_{W}$ is high, indicating more gas produced relative to water production.

\section{Production design}

In this study we focused on the hydrate deposits of Classes 2 that occurs at the site $\mathrm{SH} 2$, which is also one of the most common class of hydrate accumulations in both the permafrost and in the oceans (Moridis and Reagan, 2007a; Moridis et al., 2009a). Note that the reference case of Class 2 accumulation is confined between a permeable overburden and a permeable underburden. Without confining boundaries of impermeable strata, gas production can be disappointing because flow through the boundaries limits the effectiveness of depressurization and leads to large production volumes of undesirable water (Moridis and Kowalsky, 2006; Moridis et al., 2009a). Lack of a confining overburden could lead to gas loss though the overburden toward the surface (Moridis et al., 2009a).
A same configuration of well system is used in this study for the gas production from the $\mathrm{SH} 3$ hydrate deposit. It is a modification of the well design used in the previous hydrate production research (Moridis et al., 2009a). The perforated interval covers the mid section ( $14 \mathrm{~m}$ ) of the well in the HBL that is overlain and underlain by the permeable WZs (Fig. 2). This design has significant advantages: the configuration impedes water in the WZs from flow directly into the well in the early stage of the production, thus may effectively reduce the water production as well as the production cost. This design can cause significant dissociation around the well and yield the largest production rates in a shot run, but when the hydrate layer around the well is broken through, it may result in a sharp drop in rates of hydrate dissociation and gas production, and more water produced.

An earlier study appears to indicate that depressurization is the most promising dissociation method in the majority of hydrate deposits because of its simplicity, its technical and economic effectiveness, the fast response of hydrates to the rapidly propagating pressure wave, the near-incompressibility of water, and the large heat capacity of water (Moridis and Sloan, 2007; Moridis et al., 2007). The other dissociation methods can enhance gas production from hydrate deposits when they are used in conjunction with depressurization (Li et al., 2010), but it is not clear that a strategy using a huff-and-puff method at a vertical well in Shenhu hydrate production. In this study, a huff-and-puff method is used to produce gas from the hydrate deposits in the Shenhu area and discussed in the following part.

\section{Numerical models and simulation approach}

The numerical studies in this paper were conducted using the TOUGH + HYDRATE simulator (Moridis et al., 2009b). This code can model the non-isothermal hydration reaction, phase behavior, and flow of fluids and heat under conditions typical of natural $\mathrm{CH} 4-$ hydrate deposits in complex geologic media. It includes both an equilibrium and a kinetic model (Kim et al., 1987; Clarke and Bishnoi, 2000) of hydrate formation and dissociation. The model accounts for heat and up to four mass components (i.e., water, $\mathrm{CH}_{4}$, hydrate, and water-soluble inhibitors such as salts or alcohols) that are partitioned among four possible phases: gas, aqueous liquid, ice, and hydrate. A total of 15 states (phase combinations) can be described by the code, which can handle any combination of hydrate dissociation mechanisms and can describe the phase changes and steep solution surfaces that are typical of hydrate problems (Moridis et al., 2009b).

The geologic system in this study corresponds to a location at the drilling site of SH2 in Shenhu area where the sea floor is at an elevation of $\mathrm{z}=-1235 \mathrm{~m}$. The HBL is $40 \mathrm{~m}$ thick, and overlain by a permeable overburden of $188 \mathrm{~m}$ thick and underlain by a permeable zone.

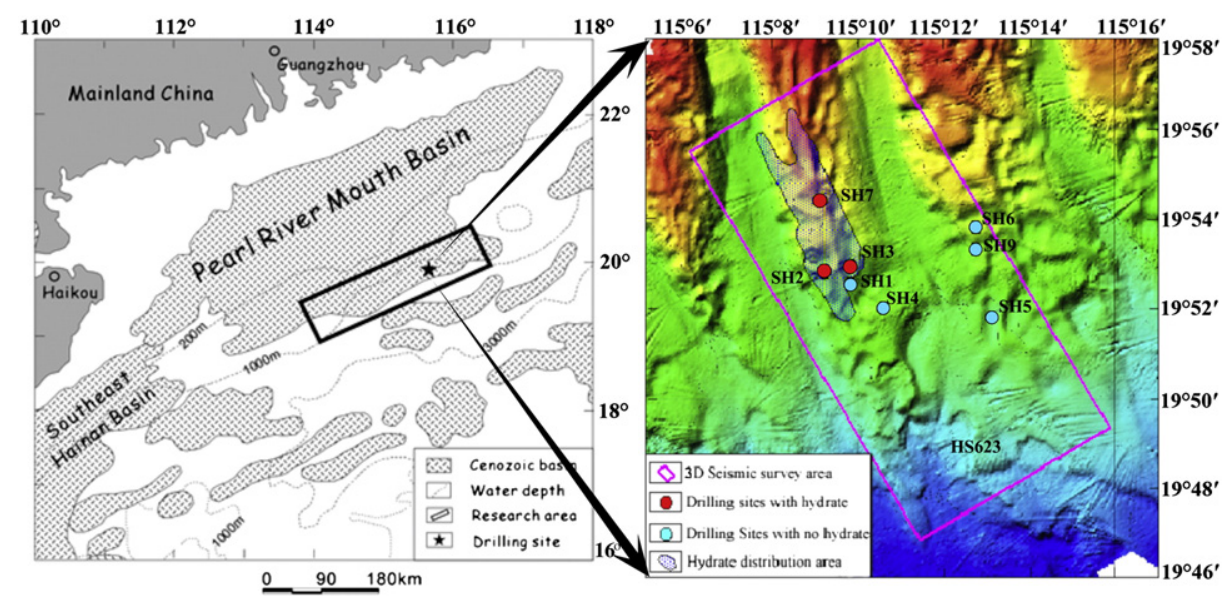

Fig. 1. Location of research field and drilling site in Shenhu area on northern continental slope of the South China Sea (Wu et al., 2008, 2010). 
(a) Production Stage

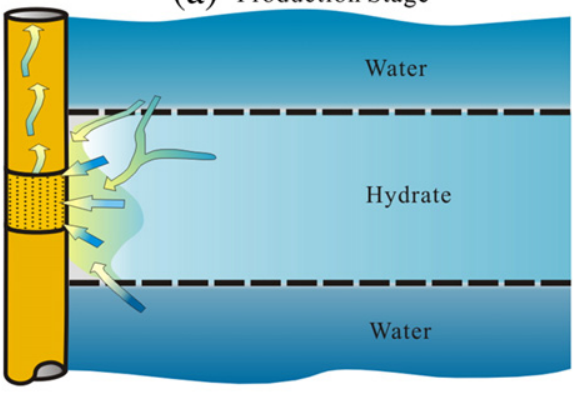

(c) Production Stage

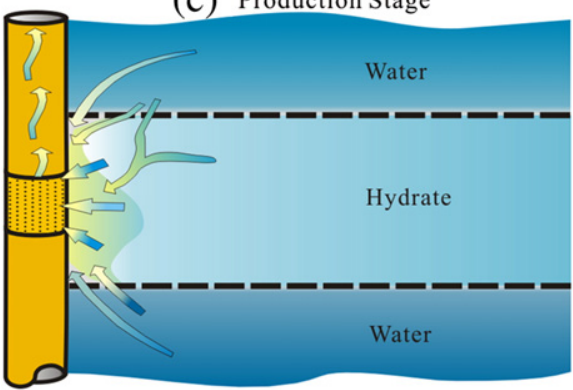

(b) Injection Stage

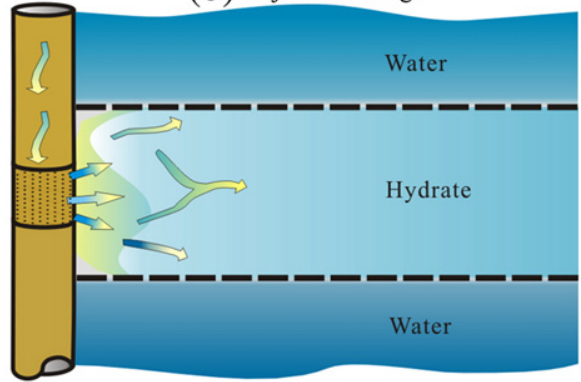

(d) Injection Stage

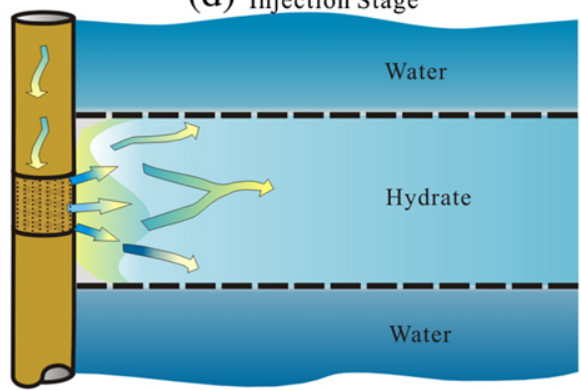

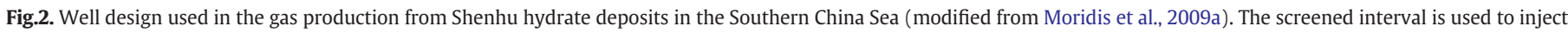
hot water in the huff-and-puff operations.

Both the overburden and underburden are unbounded and typical of water zones (WZs).

The geometry and configuration of the Class 2 system at the drilling site of SH2 are shown in Fig. 3. A 20 m overburden was considered in the simulations to allow heat exchange with the laminar hydrate deposit during a 3-yr long production period. Similarly, a 20 m underburden was sufficient to provide accurate estimates of heat transfer compared to that of gas production from hydrate accumulation in the Ulleung Basin of the Korean East Sea (Moridis et al., 2009a). The acceptability

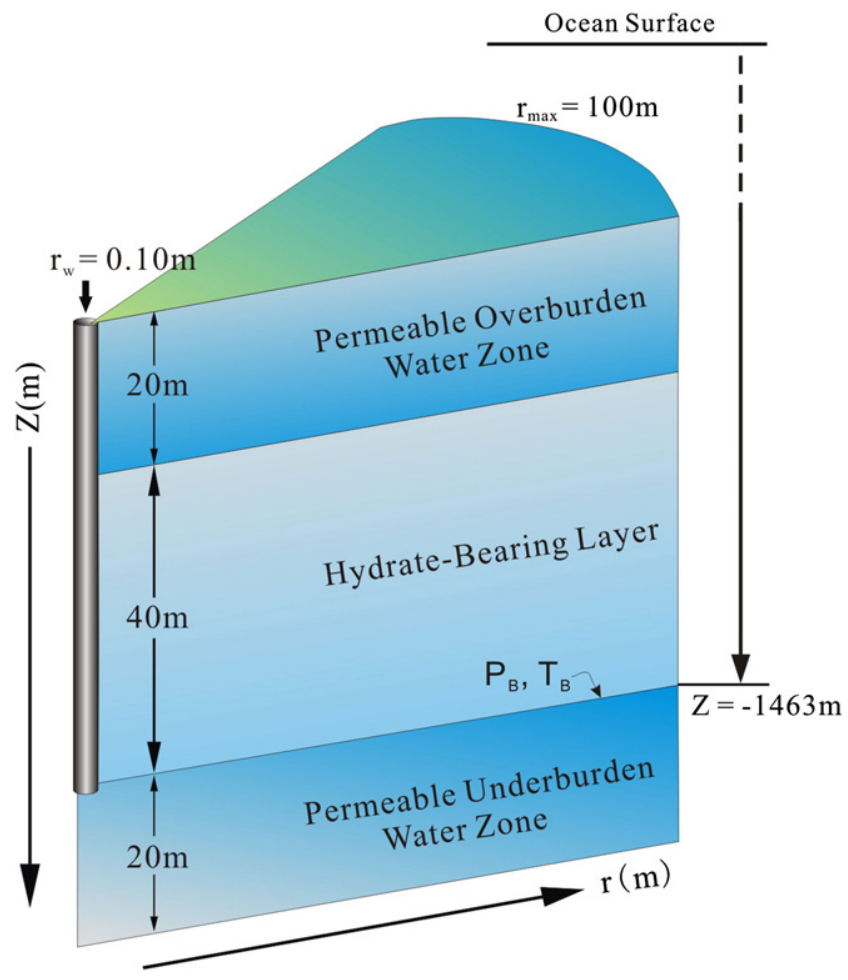

Fig.3. A schematic of the Shenhu hydrate deposits simulated in this study (modified from Moridis et al., 2009a). is approved in the simulations. The well at the center of this cylindrical hydrate deposit had a radius $r_{w}=0.1 \mathrm{~m}$. A no-flow boundary (of fluids and heat) was applied at the reservoir at radius $r_{\max }=100 \mathrm{~m}$, we also think the scale is enough for thermal transfer and fluid flow in production duration of 3 years by learning efficiency of heat transfer and previous research (Li et al., 2010; Su et al., 2011).

The same grid and media properties were used in the simulations. The cylindrical domain was discretized into $105 \times 242=25,410$ gridblocks in $(r, z)$, of which 25,200 were active (the remaining being boundary cells). The uppermost and lowermost layers corresponded to constant $T$. Because the vicinity of the wellbore had been shown to be critically important to production (Moridis et al., 2009a), a very fine discretization was used, and the interval increased exponentially along the $\mathrm{r}$ direction. The HBL was subdivided into segments of $\Delta z=0.25 \mathrm{~m}$ each along the $z$-direction for accurate predictions, but a coarser discretization along the $\mathrm{z}$ axis is permissible in the WZ (Moridis et al., 2009a). We also assumed the hydrate dissociation is an equilibrium reaction (Kim et al., 1987; Moridis et al., 2009a). The well design and important parameters were referenced from the early research (Moridis et al., 2009a).

The initial conditions in the reservoir were determined by following the initialization process described by Moridis et al. (2007, 2009a). Knowing (a) the elevation at the base of the HBL, and (b) some temperatures (Table 1), we determined the local geothermal gradient $\mathrm{G}_{\mathrm{T}}$ as $0.047^{\circ} \mathrm{C} / \mathrm{m}$, and delineated the temperature profile at site $\mathrm{SH} 2$. Then the pressure profile was obtained by means of a short simulation with the temperature, salinity, and hydrate saturation.

\section{A huff-and-puff production}

Thermal stimulation is considered as a complementary way for dissociating hydrate by depressurization due to the limitation of thermal conduction in porous sediment (Moridis et al., 2009a; Su et al., 2011). Heat conducts along the $z$-axis direction from the heated well but fluids (water and gas) flow inversely. There is hereby a possibility that heat may be taken back by fluids flowing towards the well before it reaches the hydrate dissociation front, and thus the heat affecting range will be greatly undermined (Su et al., 2011). The former research shows that the heat affecting range is generally are very small and most heat is 
Table 1

Reference hydrate deposit properties and parameters in simulations.

\begin{tabular}{|c|c|}
\hline Parameter & Value \\
\hline $\begin{array}{l}\text { Water zone (WZ) thickness (overburden \& } \\
\text { underburden) }\end{array}$ & $20 \mathrm{~m}$ \\
\hline Hydrate zone (HBL) thickness & $40 \mathrm{~m}$ \\
\hline Initial pressure $P_{B}$ (at base of $\mathrm{HBL}$ ) & $1.497 \times 10^{7} \mathrm{~Pa}$ \\
\hline Initial temperature $T_{B}$ (at base of $\mathrm{HBL}$ ) & $288.02 \mathrm{~K}\left(14.87^{\circ} \mathrm{C}\right)$ \\
\hline Gas composition & $100 \% \mathrm{CH}_{4}$ \\
\hline Initial saturations in the $\mathrm{HBL}$ & $S_{H}=0.40, S_{A}=0.60$ \\
\hline Water salinity (mass fraction) & 0.030 \\
\hline $\begin{array}{l}\text { Intrinsic permeability } k_{r}=k_{z}(\mathrm{HBL} \\
\text { and WZ) }\end{array}$ & $1.0 \times 10^{-14} \mathrm{~m}^{2}(=10 \mathrm{mD})$ \\
\hline Grain density $\rho_{R}(\mathrm{HBL}$ and WZ) & $2600 \mathrm{~kg} / \mathrm{m}^{3}$ \\
\hline Porosity $\varphi$ (HBL and WZ) & 0.38 \\
\hline Hydraulic diffusion $k_{g}$ (Cathles, 2007) & $k_{g}=k / \varphi C_{g} \mu_{g}$ \\
\hline Compressibility $C_{g}$ & \\
\hline $\begin{array}{l}\text { Dry thermal conductivity } k_{\Theta R D} \\
\text { (all formations) }\end{array}$ & $1.0 \mathrm{~W} / \mathrm{m} / \mathrm{K}$ \\
\hline $\begin{array}{l}\text { Wet thermal conductivity } k_{\Theta R W} \\
\text { (all formations) }\end{array}$ & $3.1 \mathrm{~W} / \mathrm{m} / \mathrm{K}$ \\
\hline $\begin{array}{l}\text { Composite thermal conductivity model } \\
\text { (Moridis et al., 2007) }\end{array}$ & $\begin{array}{l}k_{\Theta C}=k_{\Theta R D}+\left(S_{A}^{1 / 2}+S_{H}^{1 / 2}\right)\left(k_{\Theta R W}-\right. \\
\left.k_{\Theta R D}\right)+\varphi S_{I} k_{\Theta I}\end{array}$ \\
\hline $\begin{array}{l}\text { Capillary pressure model (van Genuchten, } \\
\text { 1980) }\end{array}$ & $\begin{array}{l}P_{\text {cap }}=-P_{0}\left[\left(S^{*}\right)^{-1 / \lambda}-1\right]^{-\lambda} S^{*}= \\
\left(S_{A}-S_{i r A}\right) /\left(S_{m \times A}-S_{i r A}\right)\end{array}$ \\
\hline$S_{i r A}$ & 1 \\
\hline$\lambda$ & 0.45 \\
\hline$P_{0}$ & $10^{5} \mathrm{~Pa}$ \\
\hline \multirow{2}{*}{$\begin{array}{l}\text { Relative permeability model (Moridis et } \\
\text { al., 2008) }\end{array}$} & $k_{r A}=\left(S_{A}^{*}\right)^{n}$ \\
\hline & $\begin{array}{l}k_{r G}=\left(S_{G}^{*}\right)^{n} \\
S_{A}^{*}=\left(S_{A}-S_{i r A}\right) /\left(1-S_{i r A}\right) \\
S_{G}^{*}=\left(S_{G}-S_{i r G}\right) /\left(1-S_{i r A}\right) \\
\text { OPM model }\end{array}$ \\
\hline$n$ (Moridis et al., 2008) & 5 \\
\hline$S_{i r G}$ & 0.03 \\
\hline$S_{i r A}$ & 0.30 \\
\hline
\end{tabular}

wasted. Therefore this simultaneous heating and producing way is unfeasible practically for producing gas from hydrate deposits (Su et al., 2011). It may be worse and technically unpractical if the hydrate dissociation is induced by continuously injecting hot water at a single well. The bottom-hole pressure should be slighter lower than that in reservoir in order to produce gas, which just violates the need for injecting water. But it may be viable to dissociate hydrate by alternately producing fluids and injecting hot water (referred to as huff-and-puff method).

Huff-and-puff widely used in petroleum industry is designed to produce gas from the hydrate deposits by combining mass production and hot water injection. The operations of production and injection are circulatory through the same screened interval of the well shown in Fig. 2. Production stops for injecting hot water, and then injection stops for producing fluids. In each circle the cumulative mass produced should be higher than the cumulative mass of water injected. The rate for water injection should be very small due to the low intrinsic permeability of the HBL at Shenhu area. High injection rate may incur secondary hydrate formation at the front of hydrate dissociation and even sediment failure. Of course, the rate for mass production should be strictly controlled according to the water injection rate. High production rate may incur negative pressure in the production well and excessive water as byproduct. Herewith, we recommend the rate values should obey a relation of $1.2 \times Q_{I n j} \frac{t_{I n j}}{t_{I n j}}<Q_{\text {Pro }}<1.8 \times Q_{I n j} \frac{t_{I n j}}{t_{I n j}}$ ( $Q_{\text {Pro }}$ is production rate and $Q_{n n j}$ is injection rate).

\subsection{Production scheme of $1_{P} 2_{I}$}

Fluids production and water injection are operated alternately to get gas produced and hydrate dissociated by heat stimulation. Figs. 4 and 5 show performance of the hydrate deposits dissociated by huff-and-puff operations of 1-day production and 2-day injection $\left(1_{\mathrm{P}} 2_{\mathrm{I}}\right)$ in the first tentative study. Water of $80^{\circ} \mathrm{C}$ is injected at a

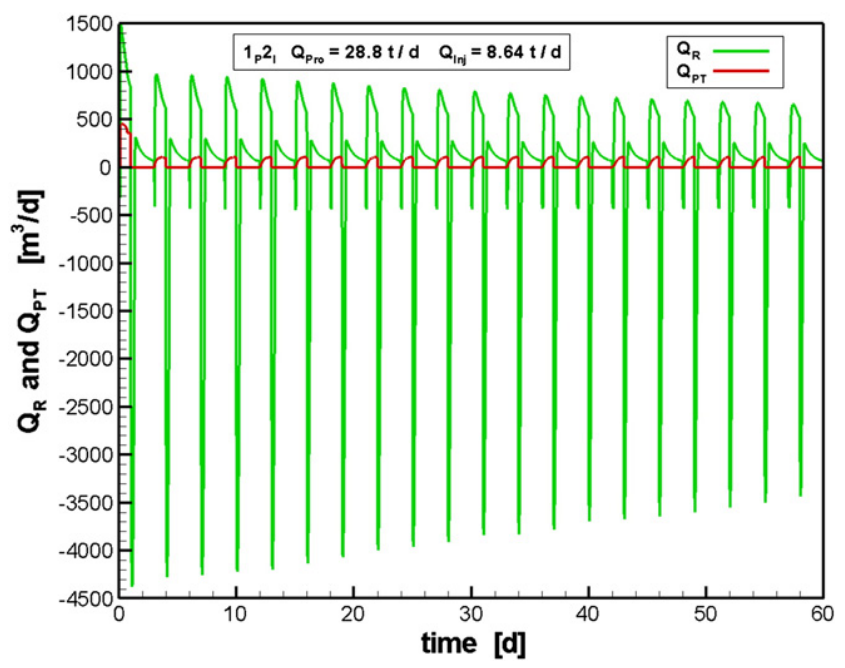

Fig.4. Evolution of gas release rate from hydrate deposits $Q_{R}$ and gas production rate $Q_{P T}$ by huff-and-puff of $1_{\mathrm{P}} 2_{\mathrm{I}}$.

constant rate of $0.033 \mathrm{~kg} / \mathrm{s}(=8.64 \mathrm{t} / \mathrm{d}$ ) while the fluids (water plus gas) are produced at a constant mass rate of $0.1 \mathrm{~kg} / \mathrm{s}(=28.8 \mathrm{t} / \mathrm{d})$. To get enough porous space for water injection, we start this operation by 1-day producing, and then convert to 2-day injection in the simulation. The zigzag type of $Q_{R}$ in Fig. 4 and $V_{R}$ in Fig. 5 indicate the alternate production and injection that resulting in gas releasing and secondary hydrate formation.

In the first time period ( 3 days) of the huff-and-puff operation both gas release and gas production are intensive. The volume of gas produced at the well $\Delta V_{P T}^{1}$ is $400 \mathrm{~m}^{3}$ (pointed by the first and highest gas producing rate in Fig. 4 and the first jump of $V_{P T}$ in Fig. 5) but the volume of gas released from hydrate $\Delta V_{R^{\prime}}^{1}$ is $1196 \mathrm{~m}^{3}$ (shown by the maximum peak in Fig. 4 and the first peak of $V_{R}$ in Fig. 5) within the same production interval (1 day), which suggests that the hydrate dissociation is induced by depressurization during the production process and that the released gas can not be pumped completely; hereafter water injection of 2 days is started, but secondary hydrate forms before gas releases from the hydrate because of rapid pressure increase caused by water injection. The volume of gas forming the secondary hydrate $\Delta V_{F H^{\prime}}^{1}$ is $1060 \mathrm{~m}^{3}$ in the initial $8 \mathrm{~h}$, which is calculated by the peak value of $1196 \mathrm{~m}^{3}$ minus the smallest value of $136 \mathrm{~m}^{3}$ of $V_{R}$ in Fig. 5. However, volume of gas released from the hydrate deposits

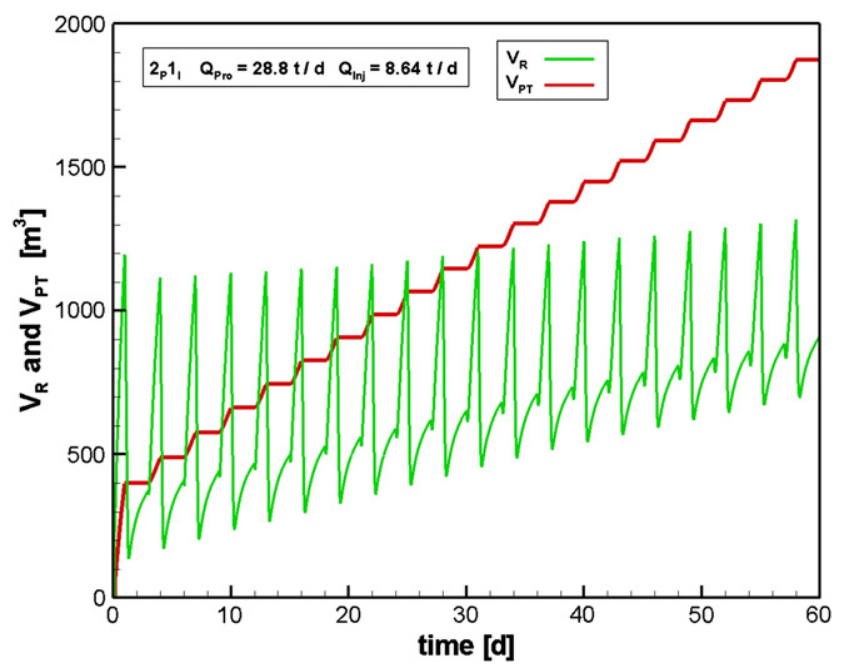

Fig.5. Volume of gas released from hydrate deposits $V_{R}$ and gas production $V_{P T}$ by huffand-puff of $1_{\mathrm{P}} 2_{\mathrm{I}}$. 
$\Delta V_{R^{\prime \prime}}^{1}$ in the remaining $40 \mathrm{~h}$ is $237 \mathrm{~m}^{3}$ (shown by the first positive slope of $V_{R}$ in Fig. 5) and much less $\Delta V_{F H^{\prime}}^{1}$ of $1060 \mathrm{~m}^{3}$. The amount of residual free gas $\left(V_{R}^{1}=\Delta V_{R^{\prime}}^{1}-\Delta V_{P T}^{1}=1196-400=796 \mathrm{~m}^{3}\right)$ in the reservoir at the end of production is less than that of gas converted into secondary hydrate at the beginning of water injection process $\left(\Delta V_{F H^{\prime}}^{1}=1060 \mathrm{~m}^{3}\right)$. Thus we can conclude that the gas forming the secondary hydrate is partially from dissolved gas, $\Delta V_{F H^{\prime}, F G}^{1}=\Delta V_{F H^{\prime}}^{1}-V_{R}^{1}=1060-796=264 \mathrm{~m}^{3}$. The superscript " 1 " points the first time-period of the huff-and-puff operation, the subscripts $R^{\prime}$ and $R^{\prime \prime}$ denote respectively the first and the second gas release from hydrates, $\mathrm{FH}^{\prime}$ represents the first time of secondary hydrate formation in each operation period ( 3 days), and $\Delta V_{F H^{\prime}, F G}^{1}$ is the volume of dissolved gas forming the secondary hydrates.

In the second period the amplitudes of all quantities are become smaller. Gas forms secondary hydrate $\left(\Delta V_{F H^{\prime}}^{2}=14 \mathrm{~m}^{3}\right)$ in a short time interval of $<1 \mathrm{~h}$ at the very beginning of the second production operation (shown by the small negative peak of $Q_{R}$ in Fig. 4 and small drop of $V_{R}$ in Fig. 5). Volume of gas produced $\Delta V_{P T}^{2}=88 \mathrm{~m}^{3}$ (the second jump of $V_{P T}$ in Fig. 5) but released gas volume $\Delta V_{R^{\prime}}^{2}$ is $775 \mathrm{~m}^{3}$ (the second peak of $V_{R}$ in Fig. 5) during this production time interval ( 1 day). By comparing the peaks in Figs. 4 and 5 of this time interval, we know much of the released gas can not be produced effectively due to the low hydraulic diffusion of the porous medium. Then the operation is adjusted to water injection. Initially free gas of $943 \mathrm{~m}^{3}$ in the reservoir is converted to secondary hydrate (referred as $\Delta V_{F H^{\prime \prime}}^{2}$ ) due to pressure increase, and gas is released from hydrate due to the heat stimulation and $\Delta V_{R^{\prime \prime}}^{2}=237 \mathrm{~m}^{3}$ during this injection interval. The unexpected high $\Delta V_{F H^{\prime \prime}}^{2}\left(=943 \mathrm{~m}^{3}\right)$ is imaged by the second and big negative peak of $Q_{R}$ in Fig. 4 and the second rapid drop from the peak point of $V_{R}$ in Fig. 5. $\Delta V_{R^{\prime \prime}}^{2}<\Delta V_{R^{\prime}}^{2}$, which implies that the hydrate dissociation in the production interval due to the slight depressurization that is for producing gas efficiently is more effective than that in hot-water injection interval due to the thermal stimulation. The volume of gas converted to secondary hydrate during water injection is greater than that dissociated from the hydrate induced by heat stimulation. The low production rate but the complicated and costly operations suggest that the "huff-and-puff" operation of $\left(1_{\mathrm{P}} 2_{\mathrm{I}}\right)$ is not promising. Likewise, the superscript " 2 " denotes the second time period of the huff-and-puff, $\mathrm{FH}^{\prime \prime}$ represents the secondary hydrate formation in each circulatory period ( 3 days), and $\Delta V_{F H^{\prime}, F G}^{1}$ is the volume of dissolved gas forming the secondary hydrates.

\subsection{Spatial distribution features}

Because the time span of this study is short and all "phenomena" happen in a small zone that is very close to the perforated interval of the well in Fig. 2, the spatial distribution in Figs. 6 through 8 are localized in the HBL ranging from $z=-60$ to $z=-20 \mathrm{~m}$ and $r<5 \mathrm{~m}$. The amount of free gas released from hydrate deposits is very small in each period of huff-and-puff operation, thus the spatial distribution of $S_{G}$ does not have meaningful information and will not be discussed in the flowing context.

\subsubsection{Spatial distribution of $T$}

The $T$ distribution in Fig. 6 supports the low affectivity of hot water injection and also confirms the analysis above. Each separate contour plot in Fig. 6 is just at the time of ending water injection. $T$ in the dissociating zone is still lower than the background temperature and has no any clear "abnormal" change revealing the heat efficiency. This result is attributed to the low water injection rate and low heat transferring in the silt clay sediment. Furthermore, the heat reached the dissociation front has been consumed by dissociating hydrate.

\subsubsection{Spatial distributions of $S_{H}$}

Fig. 7 shows the evolution of the $S_{H}$ distribution over time in the HBL near the wellbore $(r<5 \mathrm{~m})$. The characteristics of $S_{H}$ distribution have never been seen before. These include (i) hydrate dissociation proceeding slowly and having a nearly "well-regulated" dissociation front, (ii) the dissociated zone performing like a growing trapezoid during the evolution, (iii) and secondary hydrate forming at the dissociation front and being more pronounced along the $z$-axis direction and with time. The unique-looking features of (i) and (ii) are because of the small dissociated scale and heat-induced dissociation that may have same dissociation rates during the "equilibrium dissociation" simulation. Secondary hydrate is caused by pressure increase during the water injection interval; its spatial evolution indicates the general loci of injected water flow as well as transferring of pore pressure, and the temporal growth implies that the heat effect on the hydrate dissociation becomes weaker because heat transferring through conduction is more and more difficult to reach the extending dissociation front but the pressure can be elevated obviously by injecting water.
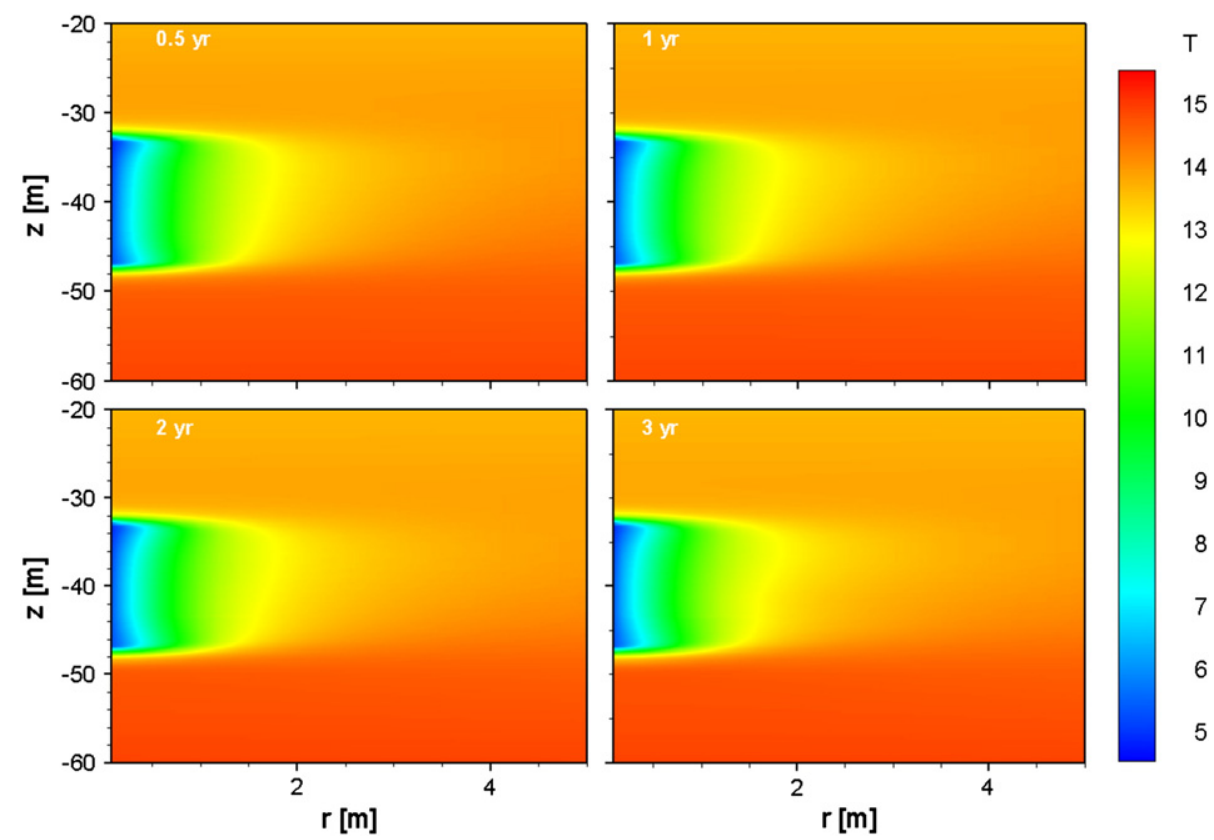

13

12

11

10

Fig.6. Evolution of temperature T during production by huff-and-puff of 1-day production and 2-day injection $\left(1_{\mathrm{P}} 2_{\mathrm{I}}\right)$. 

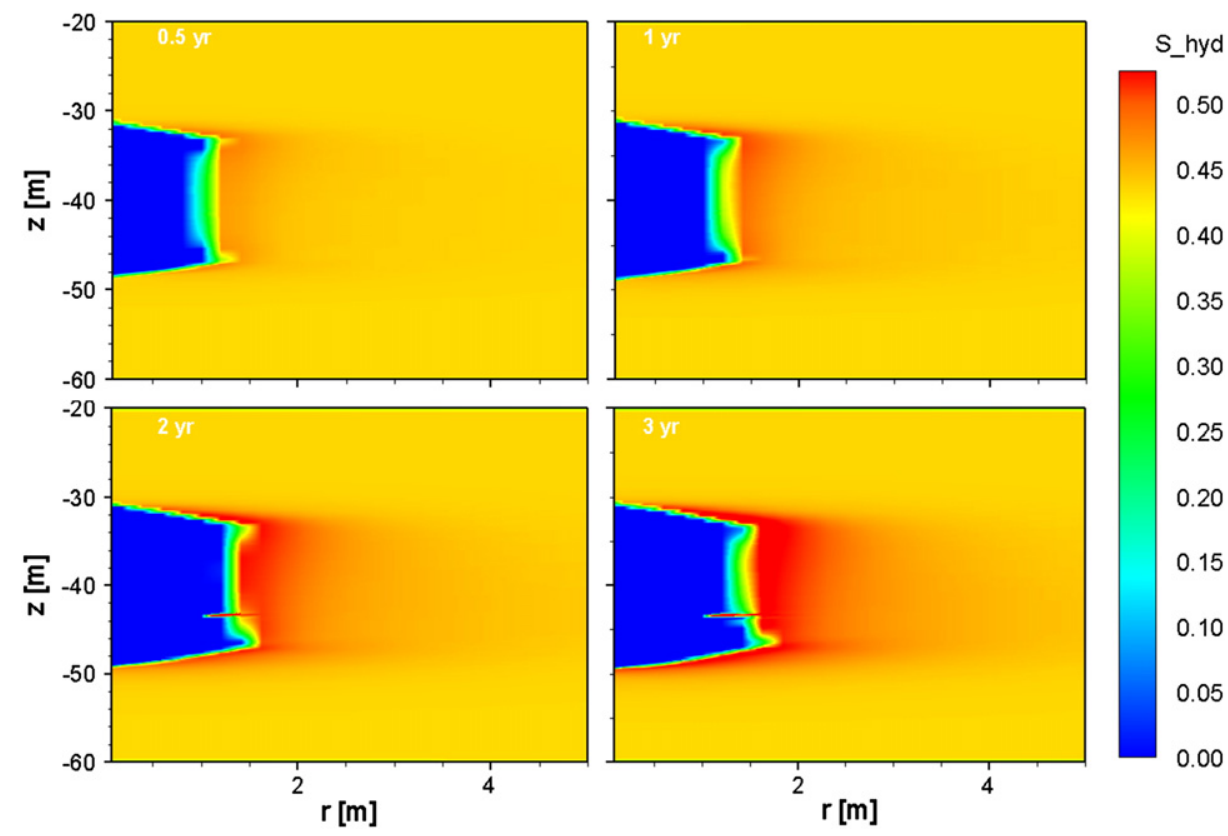

Fig.7. Evolution of hydrate saturation $S_{H}$ during production by huff-and-puff of 1 -day production and 2-day injection ( $\left.11_{\mathrm{P}} 2_{\mathrm{I}}\right)$.

\subsubsection{Spatial distributions of $X_{S}$}

The distribution of the salt concentration in Fig. 8 (shown as X_inh) illustrates the dilution effect of dissociation on salinity. Water salinity is reduced upon hydrate dissociation. The salinity reduced zone in Fig. 8 is wider than the hydrate dissociated zone in Fig. 7. A narrow blue zone indicating the most reduced salinity around the well is because of continuing removal (through production), dilution of injected water and dissociated water from hydrate, and drainage of the native saline water. The less reduced salinity (yellow zone) in the secondary hydrate zone (Fig. 7) is due to the desalination of hydrate formation. The yellow zone is pronounced along the $z$-axis direction as the operation time goes, which is consistent with the secondary hydrate that becomes more and more pronounced.

\subsection{Huff-and-puff adjustment}

The performance of gas production operated by huff-and-puff operation of $1_{\mathrm{P}} 2_{\mathrm{I}}$ discussed immediately above does not seem to be economical and of interest to industry. To further seek the effect of intermittent hot water injection on production performance, we investigate the gas production ( $Q_{P T}$ and $V_{P T}$, the absolute criterion) and production efficiency ( $R_{G W}$, the relative criterion) by adjusting the length of the time interval for water injection and the mass rates of production and injection, but keep the mass ratio of production to water injection $\left(Q_{\mathrm{Pro}} \cdot \Delta t_{\mathrm{Pro}} / \mathrm{Q}_{I n j} \cdot \Delta t_{I n j}\right)$ constant. The temperature of injected water is still $80^{\circ} \mathrm{C}$. In Figs. 9 through $11,1_{\mathrm{p}} 1_{\mathrm{I}}$ represents an operation of 1-day production (i.e. $\Delta t_{\mathrm{Pro}}=1$ day ) and 1-day injection
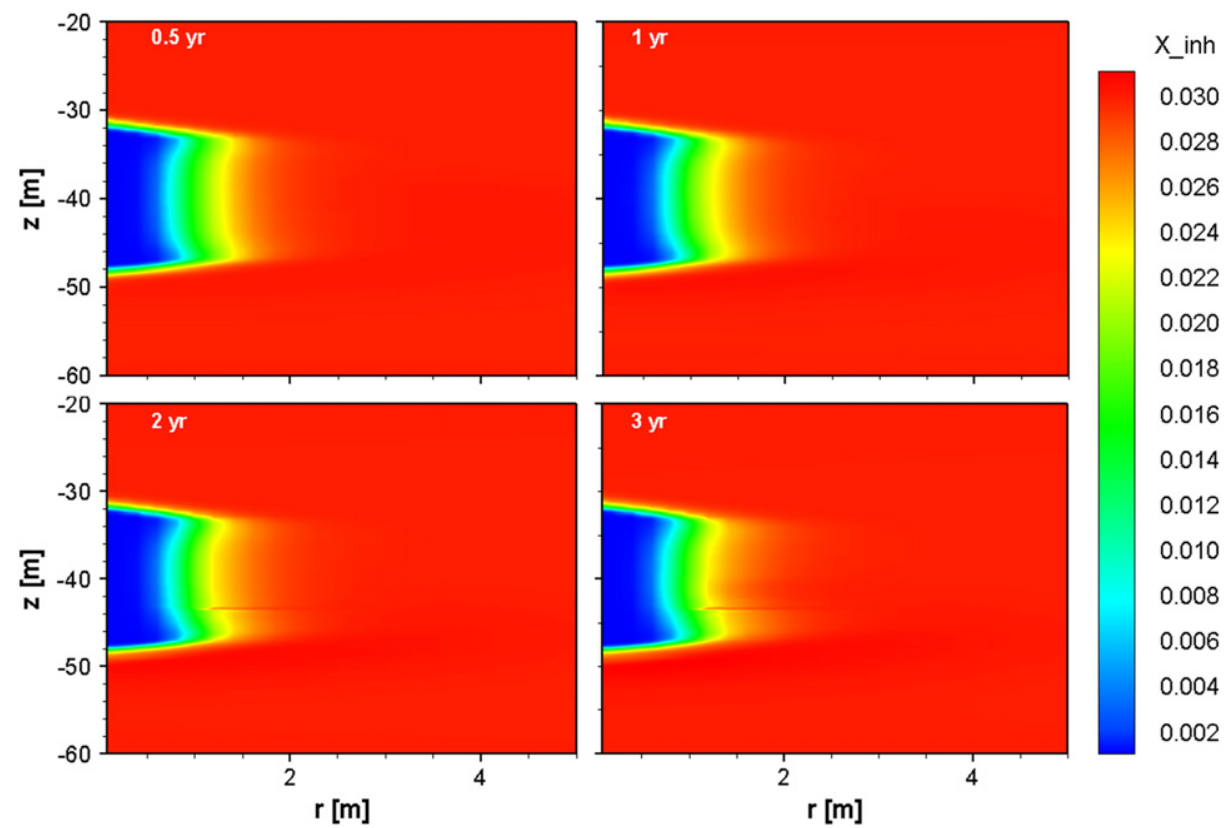

Fig.8. Evolution of mass fraction of salt-inhibitor during production by huff-and-puff of 1-day production and 2-day injection ( $\left.1_{\mathrm{P}} 2_{\mathrm{I}}\right)$. 


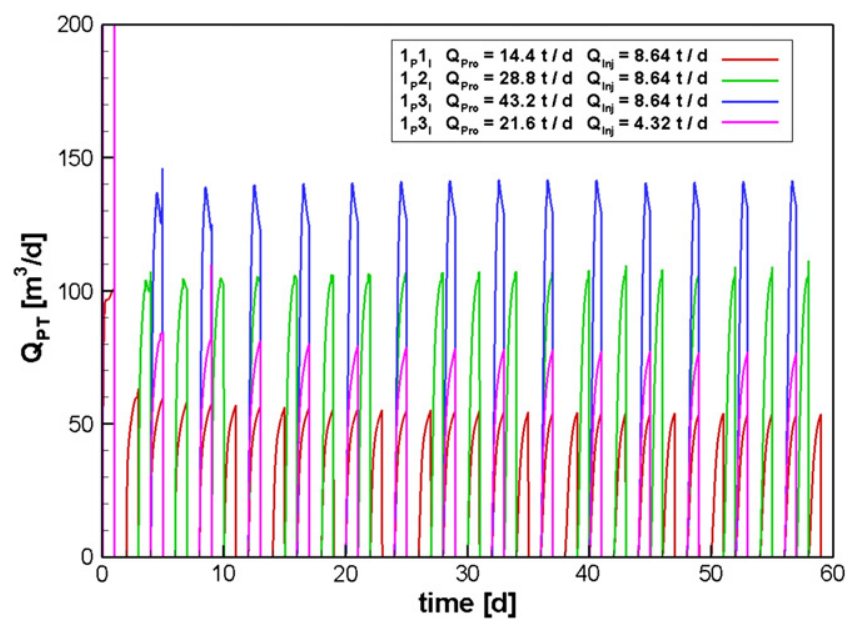

Fig.9. Evolution of gas production rate $Q_{P T}$ at the well by huff-and-puff.

(i.e. $\Delta t_{I n j}=1$ day), $1_{\mathrm{P}} 2_{\mathrm{I}}$ is a scheme of 1 -day production and 2-day injection, and $11_{\mathrm{P}} 3_{\mathrm{I}}$ denotes an scheme of 1-day production and 3-day injection; $Q_{P r o}$ is fluids production rate and $Q_{I n j}$ is hot water injection rate.

Fig. 9 shows effect of different huff-and-puff operations on total gas production rate $Q_{P T}$ at the well. $Q_{P T}$ suggests that $1_{\mathrm{P}} 3_{\mathrm{I}}$ is the best scheme and $1_{P} 1_{I}$ is the worst one. The average peak value of $Q_{P T}$ in the operation of $1_{\mathrm{P}} 3_{\mathrm{I}}$ is approximate to $140 \mathrm{~m}^{3} / \mathrm{d}$ but only $50 \mathrm{~m}^{3} / \mathrm{d}$ in $1_{\mathrm{P}} 1_{\mathrm{I}}$ operation. The effect sequence of all operations in this study is $1_{\mathrm{P}} 3_{\mathrm{I}}, 1_{\mathrm{P}} 2_{\mathrm{I}}$, and $1_{\mathrm{P}} 1_{\mathrm{I}}$, which suggests that for a fixed production time interval $Q_{P T}$ can be increased by prolonging water injection time $\Delta t_{I n j}$. However, for a same operation period of $1_{\mathrm{P}} 3_{\mathrm{I}}$, the higher $Q_{\text {Pro }}(=43.2 \mathrm{t} / \mathrm{d})$ and higher $Q_{I n j}(=8.64 \mathrm{t} / \mathrm{d})$ have positive effect on $Q_{P T}$. The ratio of $Q_{P T}(=140 / 75=1.87)$ generally has the same value with that of the production rates $(=43.2 / 21.6=2)$ or injection rate $(=8.64 / 4.32=2)$. The higher $Q_{P T}$ may be attributed to the higher gas release rate $Q_{R}$ induced by heat stimulation.

This behavior of Shenhu hydrate deposits in the SCS is also illustrated by the evolution of the total cumulative volume of produced gas $V_{P T}$ and gas released from hydrate $V_{R}$. Fig. 10 shows effect of the huff-and-puff operations on $V_{P T}$ and $V_{R}$. $V_{P T}$ is the highest in the operation of $1_{\mathrm{P}} 3_{\mathrm{I}}\left(Q_{P r o}=43.2 \mathrm{t} / \mathrm{d}\right.$ and $\left.Q_{I n j}=8.64 \mathrm{t} / \mathrm{d}\right)$ but depressed as the injection time is reduced. Thus the sequential order of $V_{P T}$ in the huffand-puff operations is $1_{\mathrm{P}} 3_{\mathrm{I}}\left(Q_{P r o}=43.2 \mathrm{t} / \mathrm{d}\right.$ and $\left.Q_{I n j}=8.64 \mathrm{t} / \mathrm{d}\right), 1_{\mathrm{P}} 2_{\mathrm{I}}$, $1_{\mathrm{P}} 1_{\mathrm{I}}$, and $1_{\mathrm{P}} 3_{\mathrm{I}}\left(Q_{\text {Pro }}=21.6 \mathrm{t} / \mathrm{d}\right.$ and $\left.Q_{I n j}=4.32 \mathrm{t} / \mathrm{d}\right)$. The maximum gas

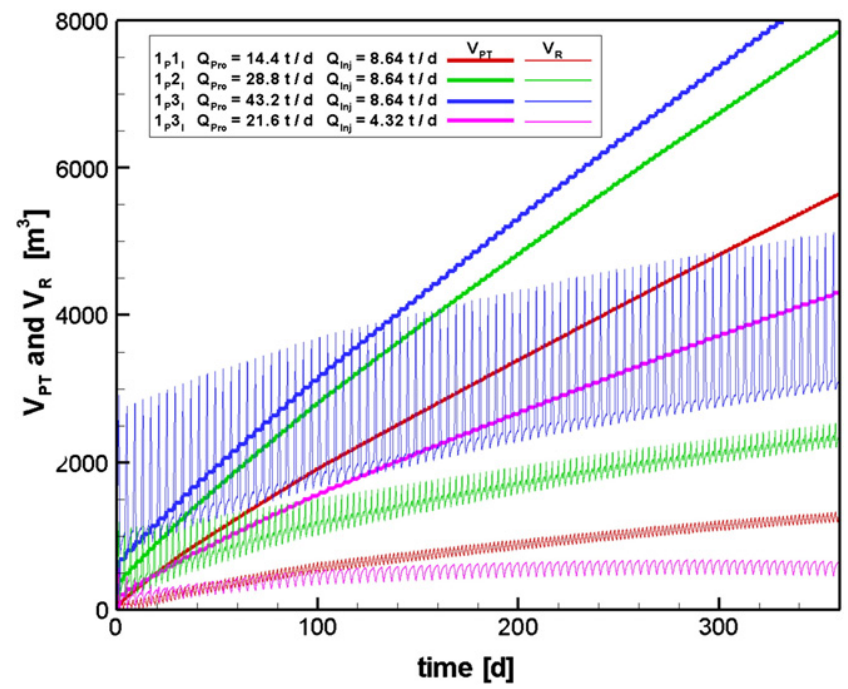

Fig.10. Evolution of cumulative volume of $\mathrm{CH}_{4}$ produced at the well $Q_{P T}$ and cumulative volume $\mathrm{CH}_{4}$ released from gas hydrates $Q_{R}$ in the operations of huff-and-puff.

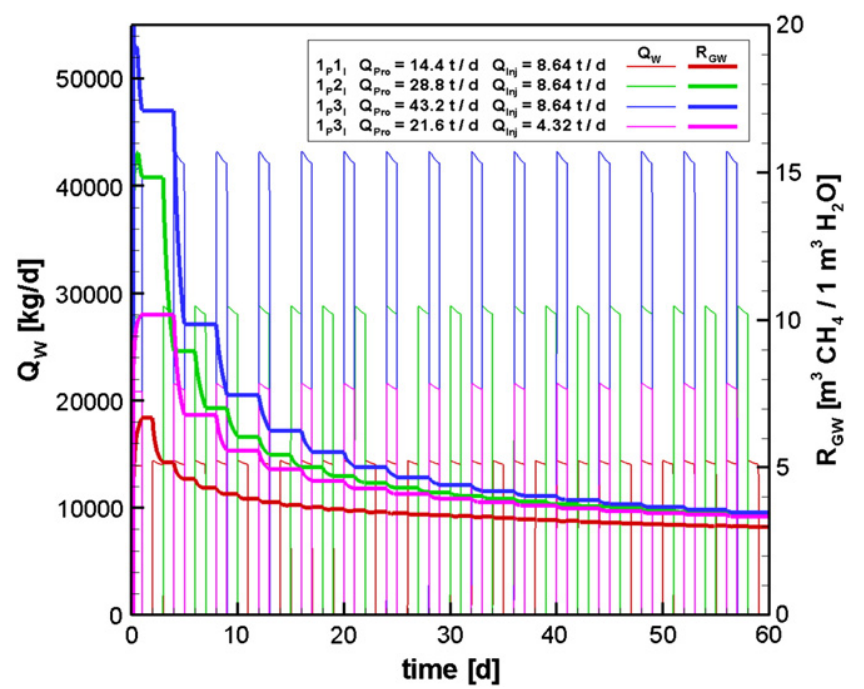

Fig.11. Evolution of water production rate $Q w$ and the ratio $R_{G W}$ of cumulative volume of $\mathrm{CH}_{4}$ production $V_{P T}$ to cumulative volume of water production $M_{W}$.

production in 1 year (360 days) is $\sim 8000 \mathrm{~m}^{3}$ in the scheme of $1 \mathrm{p} 3 \mathrm{I}$ ( $Q_{\text {Pro }}=43.2 \mathrm{t} / \mathrm{d}$ and $Q_{I n j}=8.64 \mathrm{t} / \mathrm{d}$ ) and much less than that produced by depressurization. The sequential order of $V_{R}$ is the same with that of $V_{P T}$. The fluctuation amplitudes of $V_{R}$ are related to mass of hot water injected. More water is injected and more hydrate is dissociated by heat from hot water. Meanwhile, injecting more water (long time injection) inevitably results in more secondary hydrate. Dissociation rate is possibly be mitigated because heat flow does not effectively reach the dissociation front if the injection rate of hot water is low. That's why the volume of dissociated gas under the scheme of $1_{\mathrm{P}} 1_{\mathrm{I}}$ is greater than that in the operation of $1 \mathrm{P} 3 \mathrm{I}\left(Q_{\text {Pro }}=21.6 \mathrm{t} / \mathrm{d}\right.$ and $Q_{n j}=4.32 \mathrm{t} / \mathrm{d}$ ). As a whole, $V_{R}$ is much lower than $V_{P T}$ and thus much gas produced is from the dissolved gas sink.

Fig. 11 shows the effect of the huff-and-puff operations on water production rate $Q_{W}$ and gas production efficiency relative to water $R_{G W}$. $Q_{W}$ is positively correlated to $Q_{\text {Pro }}$ but $R_{G W}$ is negative to $Q_{P r o}$. The maximum $Q_{W}$ exceeds $42,000 \mathrm{~kg} / \mathrm{d}$ (=42 ton $/ \mathrm{d} \sim 42 \mathrm{~m}^{3} / \mathrm{d}$ ) within each production interval of $1_{\mathrm{P}} 3_{\mathrm{I}}\left(Q_{P r o}=43.2 \mathrm{t} / \mathrm{d}\right.$ and $\left.Q_{\operatorname{Inj}}=8.64 \mathrm{t} / \mathrm{d}\right)$ but the average $R_{G W}$ is $\sim 5$. That means that a total gas of $210 \mathrm{~m}^{3}$ can only be produced while water of 25.92 tons is injected in each period (4 days) of the huff-and-puff operation. By considering the huge water production and water injection versus the small gas production, we think the huff-and-puff operation to the Shenhu hydrate deposits are not of attraction.

\section{Conclusions}

We investigated a huff-and-puff production potential of gas hydrate deposits at drilling site of $\mathrm{SH} 2$ in Shenhu area on the northern continental slope of South China Sea. A vertical well was designed to produce gas from the perforated interval at middle section of the well in the HBL. We dissociate hydrate by alternately producing fluids and injecting hot water. Thus simulations indicated that injecting hot water did not seem as an effective way to dissociate hydrate by the heat stimulation. Most gas released from the hydrate was indeed mainly attributed to depressurization during production process. The volume of gas released from hydrate due to the heat injection was less than that converted to secondary hydrate because of the pressure elevation. In the first 60 days run by huff-and-puff operations of $1_{\mathrm{P}} 2_{\mathrm{I}}$ ( 1 day production and 2 day injection), the average gas production rate $\bar{Q}_{P T}=93 \mathrm{~m}^{3} / \mathrm{d}$ and $V_{P T}=1875 \mathrm{~m}^{3}, Q_{W}$ exceeded $28,000 \mathrm{~kg} / \mathrm{d}\left(=28 \mathrm{t} / \mathrm{d} \sim 28 \mathrm{~m}^{3} / \mathrm{d}\right)$, the volumetric ratio of gas to water production decreases and $R_{G W}=3.3$ at $\mathrm{t}=60 \mathrm{~d}$. Furthermore, water of $345.6 \mathrm{t}$ was injected in the 60 days. The hydrate dissociation 
was very slow and the dissociation radius was $\sim 1 \mathrm{~m}$ after a 3 year production by the huff-and-puff method. Increase injection time and heat injection rate were good to hydrate dissociation. The maximum $V_{P T}$ is $\sim 15,949 \mathrm{~m}^{3}$ after 3 years in the scheme of $1_{\mathrm{P}} 3_{\mathrm{I}}$ but $\sim 5500 \mathrm{~m}^{3}$ gas was only released from the hydrate deposits. The absolute criterion and relative criterion suggested that gas production from the hydrate deposits by the huff-and-puff method through a vertical well were not promising and of industrial potential. A desirable huff-and-puff production may need novel production schemes and advanced well designs.

\begin{tabular}{|c|c|}
\hline \multicolumn{2}{|c|}{ Nomenclature } \\
\hline$\Delta r$ & Radial increment (m) \\
\hline$\Delta t$ & Time step size $(\mathrm{s})$ \\
\hline$\Delta z$ & Vertical discretization, i.e., in the $z$-direction ( $\mathrm{m}$ ) \\
\hline C & Specific heat $(\mathrm{J} / \mathrm{kg} / \mathrm{K})$ \\
\hline$k$ & Intrinsic permeability $\left(\mathrm{m}^{2}\right)$ \\
\hline$k_{\Theta}$ & Thermal conductivity $(\mathrm{W} / \mathrm{m} / \mathrm{K})$ \\
\hline$k_{\Theta R D}$ & Thermal conductivity of dry porous medium $(\mathrm{W} / \mathrm{m} / \mathrm{K})$ \\
\hline$k_{\ominus R W}$ & $\begin{array}{l}\text { Thermal conductivity of fully saturated porous medium } \\
(\mathrm{W} / \mathrm{m} / \mathrm{K})\end{array}$ \\
\hline$M_{W}$ & $\begin{array}{l}\text { Cumulative mass of water released into the ocean through } \\
\text { the annular gravel pack }(\mathrm{kg})\end{array}$ \\
\hline$P$ & Pressure $(\mathrm{Pa})$ \\
\hline$Q_{I n j}$ & Mass rate of injected warm water at the well $(\mathrm{kg} / \mathrm{s})$ \\
\hline QPro & Mass rate of fluid withdrawal at the well $(\mathrm{kg} / \mathrm{s})$ \\
\hline$Q_{P T}$ & Volumetric rate of $\mathrm{CH}_{4}$ production at the well $(\mathrm{ST} \mathrm{m} / \mathrm{s})$ \\
\hline$Q_{P G}$ & Volumetric rate of free gas produced at the well $(\mathrm{ST} \mathrm{m} / \mathrm{s})$ \\
\hline$Q_{R}$ & $\begin{array}{l}\text { Volumetric rate of } \mathrm{CH}_{4} \text { release from hydrate dissociation } \\
\left(\mathrm{ST} \mathrm{m}^{3} / \mathrm{s}\right)\end{array}$ \\
\hline$Q_{W}$ & Mass rate of water produced at the well $(\mathrm{kg} / \mathrm{s})$ \\
\hline$r, z$ & Coordinates $(\mathrm{m})$ \\
\hline$r_{c}$ & $\begin{array}{l}\text { Critical radius of maximum activity around the wellbore } \\
(\mathrm{m})\end{array}$ \\
\hline$r_{w}$ & Radius of the well assembly (m) \\
\hline$r_{\max }$ & Maximum radius of the simulation domain (m) \\
\hline$R_{G W}$ & 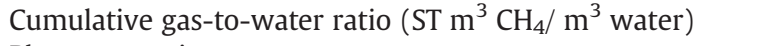 \\
\hline$S$ & Phase saturation \\
\hline$t$ & Time (days) \\
\hline$T$ & Temperature $\left(\mathrm{K}\right.$ or $\left.{ }^{\circ} \mathrm{C}\right)$ \\
\hline$V_{P T}$ & Total volume of $\mathrm{CH}_{4}$ produced at the well $\left(\mathrm{ST} \mathrm{m}^{3}\right)$ \\
\hline$V_{P G}$ & Cumulative volume of free $\mathrm{CH}_{4}$ produced at the well $\left(\mathrm{ST} \mathrm{m}{ }^{3}\right)$ \\
\hline$V_{R}$ & 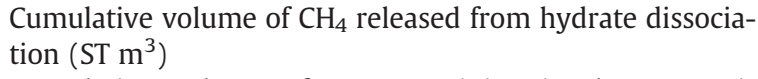 \\
\hline$V_{G}$ & $\begin{array}{l}\text { Cumulative volume of } \mathrm{CH}_{4} \text { remaining in the reservoir } \\
\left(\mathrm{ST} \mathrm{m}^{3}\right)\end{array}$ \\
\hline$X$ & Mass fraction $(\mathrm{kg} / \mathrm{kg})$ \\
\hline
\end{tabular}

$\begin{array}{ll}\text { Greek symbols } \\ \lambda & \text { van Genuchten exponent - Table } 1 \\ \varphi & \text { Porosity }\end{array}$

Subscripts and superscripts

A Aqueous phase

B HBL base

cap Capillary

G Gas phase

$H \quad$ Solid hydrate phase

irG Irreducible gas

irA Irreducible aqueous phase

Ing Injection

$n \quad$ Permeability reduction exponent - Table 1

$O B \quad$ Overburden

Pro Production

\section{Acknowledgments}

This work was supported by the National Natural Science Foundation of China (No. 41076037), Knowledge Innovation Program of Chinese Academy of Sciences (No. KGCX2-YW-805), China Geological Survey, and Lawrence Berkeley National Laboratory under the U.S. Department of Energy. We also thank the anonymous reviewers for their comments and suggestions to improve the quality of work.

\section{References}

Cathles, L.M., 2007. Changes in sub-water table fluid flow at the end of the Proterozoic and its implications for gas pulsars and MVT lead-zinc deposits. Geofluids 7, 209-226.

Clarke, M.A., Bishnoi, P.R., 2000. Determination of the intrinsic rate of methane gas hydrate decomposition. Chem. Eng. Sci. 55, 4869.

Kim, H.C., Bishnoi, P.R., Heidemann, R.A., Rizvi, S.S.H., 1987. Kinetics of methane hydrate decomposition. Chem. Eng. Sci. 42 (7), 1645

Leaute, R.P., Carey, B.S., 2007. Liquid addition to steam for enhancing recovery (LASER) of bitumen with CSS: results from the first pilot cycle. J. Can. Pet. Technol. 46 (9), 22-30.

Li, G., Moridis, G.J., Zhang, K., Li, X., 2010. Evaluation of gas production potential from marine gas hydrate deposits in Shenhu area of South China Sea. Energy Fuel 24, 6018-6033.

Li, G., Moridis, G.J., Zhang, K., Li, X., 2011. The use of huff and puff method in a single horizontal well in gas production from marine gas hydrate deposits in the Shenhu Area of South China Sea. J. Pet. Sci. Eng. 77, 49-68.

Makogon, Y.F., 1987. Gas hydrates: frozen energy. Recherche 18 (192), 1192

Makogon, Y.F., 1997. Hydrates of Hydrocarbons. Penn Well Publishing Co., Tulsa, OK.

Moridis, G.J., Kowalsky, M., 2006. Gas production from unconfined Class 2 hydrate accumulations in the oceanic subsurface. In: Max, M., Johnson, A.H., Dillon, W.P., Collett, T. (Eds.), Chapter 7, in Economic Geology of Natural Gas Hydrates. Kluwer Academic/Plenum Publishers, pp. 249-266.

Moridis, G.J., Reagan, M.T., 2007a. Strategies for gas production from oceanic Class 3 hydrate accumulations. OTC 18865, 2007 Offshore Technology Conference, Houston, Texas, U.S.A., 30 April-3 May 2007.

Moridis, G.J., Reagan, M.T., 2007b. Gas production from oceanic Class 2 hydrate accumulations. OTC 18866, 2007 Offshore Technology Conference, Houston, Texas, U.S.A., 30 April-3 May 2007.

Moridis, G.J., Sloan, E.D., 2007. Gas production potential of disperse low-saturation hydrate accumulations in oceanic sediments. J. Energ. Convers. Manage. 48 (6), 1834-1849.

Moridis, G.J., Collett, T., Dallimore, S., Satoh, T., Hancock, S., Weatherhill, B., 2004. Numerical studies of gas production from several methane hydrate zones at the Mallik Site, Mackenzie Delta, Canada. J. Pet. Sci. Eng. 43, 219-239.

Moridis, G.J., Kowalsky, M., Pruess, K., 2007. Depressurization-Induced gas production from Class 1 hydrate deposits. SPE J. Reserv. Eval. Eng. 10 (5), 458-481.

Moridis, G.J., Kowalsky, M., Pruess, K., 2008. TOUGH + HYDRATE v1.0 User's Manual: A code for the Simulation of System Behavior in Hydrate-Bearing Geologic Media. LBNL-00149E.

Moridis, G.J., Reagan, M.T., Kim, S.-J., Seol, Y., Zhang, K., 2009a. Evaluation of the gas production potential of marine hydrate deposits in the Ulleung Basin of the Korean East Sea. SPE J. 14 (4), 759-781 2009, SPE-110859-PA.

Moridis, G.J., Collett, T.S., Boswell, R., Kurihara, M., Reagan, M.T., Koh, C., Sloan, E.D., 2009b. Toward production from gas hydrates: current status, assessment of resources, and simulation-based evaluation of technology and potential. SPE Reserv. Eval. Eng. 12 (5), 745-771.

Moridis, G.J., Collett, T.S., Pooladi-Darvish, M., Hancock, S., Santamarina, C., Boswell, R., Kneafsey, T., Rutqvist, J., Kowalsky, M., Reagan, M.T., Sloan, E.D., Sum, A.K., Koh, C., 2011. Challenges, uncertainties and issues facing gas production from gas hydrate deposits. SPE Reserv. Eval. Eng. 14 (1), 76-112.

Sayegh, S.G., Maini, B.B., 1984. Laboratory evaluation of the $\mathrm{CO}_{2}$ huff-n-puff process for heavy oil-reservoirs. J. Can. Pet. Technol. 23 (3), 29-36.

Sloan, E.D., 1998. Clathrate Hydrates of Nautral Gases. Marcel Decker, Inc., New York, NY.

Sloan, E.D., Koh, C.A., 2008. Clathrate Hydrates of Natural Gases, third edition. CRC Press, Boca Raton, Florida.

Su, Z., Cao, Y., Wu, N., He, Y., 2011. Numerical analysis on gas production efficiency from hydrate deposits by thermal stimulation: application to Shenhu Area, South China Sea. Energies 4, 294-313.

van Genuchten, M.Th., 1980. A closed-form equation for predicting the hydraulic conductivity of unsaturated soils. Soil Sci. Soc. Am. J. 44, 892-898.

Vittoratos, E., 1991. Flow regimes during cyclic steam stimulation at Cold Lake. J. Can. Pet. Technol. 30 (1), 82-86.

Wu, N., Yang, S., Zhang, H., Liang, J., Wang, H., Su, X., Fu, S., 2008. Preliminary discussion on gas hydrate reservoir system of Shenhu Area, North Slope of South China Sea. Proceedings of the 6th International Conference on Gas Hydrates (ICGH 2008), 5700, Vancouver, British Columbia, CANADA, 6-10 July 2008.

Wu, N., Yang, S., Zhang, H., Liang, J., Wang, H., Lu, J., 2010. Gas Hydrate System of Shenhu Area, Northern South China Sea:Wire-line Logging, Geochemical Results and Preliminary Resources Estimates. OTC 20485, 2010 Offshore Technology Conference, Houston, Texas, U.S.A., 3-6 May 2010. 